\section{Saúde Comunitária para Todos}

\section{Community Health For All}

Palavras-chave: Centros Comunitários de Saúde; Participação da Comunidade; Planeamento em Saúde Comunitária; Planeamento Social

Keywords: Community Health Planning; Community Health Services; Community Participation; Social Planning

\section{Caro Editor,}

Foi com interesse que lemos o artigo 'Abordagem do Doente Difícil: O Exemplo de Zamora,'1 publicado na edição de fevereiro de 2021 da Acta Médica Portuguesa. As autoras destacam a relevância de estratégias de intervenção comunitária em psiquiatria, traduzindo-se em ganhos em saúde. ${ }^{1}$

Ao nível dos cuidados de saúde primários, uma das competências nucleares da Medicina Geral e Familiar é a orientação comunitária. ${ }^{2}$ É dever do médico de família valorizar tanto os problemas de saúde dos utentes como as necessidades da comunidade onde se inserem, atendendo aos recursos disponíveis. ${ }^{2}$

Neste sentido, torna-se relevante conhecer o conceito de 'desenvolvimento comunitário' (DC), podendo este ser útil para profissionais de saúde que desejem ampliar a intervenção na comunidade onde atuam.

Segundo Ander-Egg, DC define-se como a "técnica social de promoção do homem e de mobilização de recursos humanos e institucionais, mediante a participação ativa e democrática da população, no estudo, planeamento, e execução de programas ao nível de comunidades de base, destinados a melhorar o seu nível de vida". ${ }^{3}$

O DC deve seguir fases concretas. ${ }^{4}$ Inicia-se com informação geral e dinamização da coletividade, seguindo-se a prospeção de necessidades e recursos potenciais, sendo fundamental a identificação dos líderes locais e o seu envolvimento no projeto. Só então se deverá proceder à planificação, conjuntamente com a comunidade e seus líderes, para que aquela se torne sua propriedade. A implementação deverá ser continuamente monitorizada, terminando com a avaliação final. ${ }^{4}$

A intervenção comunitária tem um papel central no apoio a cidadãos em situação de fragilidade, quer em termos de apoio logístico, psicossocial, ou facilitando o acesso a cuidados de saúde. ${ }^{3}$ Em tempos de incerteza, e sobretudo com populações fragilizadas, o recurso à técnica de DC pode ter impactos positivos, apresentando-se como uma boa opção num futuro próximo. Uma possibilidade é promover a participação da comunidade em ações que contribuam para o controlo da pandemia. ${ }^{5} \mathrm{O}$ envolvimento direto na resolução do problema favorece o empoderamento da comunidade, constituindo uma estratégia que poderá ser considerada na orientação de políticas sociais e de saúde em prole da equidade e justiça social. ${ }^{5}$ Importa sublinhar que as estratégias de intervenção comunitária deverão sofrer ajustes à nova realidade de vivência e convivência das comunidades.

Promover o desenvolvimento das comunidades implica investir na melhoria das condições de vida e determinantes de saúde das populações, atuando diretamente nas desigualdades. Deve, assim, constituir uma preocupação de todos os profissionais de saúde.

\title{
REFERÊNCIAS
}

1. Pinto I, Moreno L. Abordagem do doente difícil: o exemplo de Zamora Acta Med Port. 2021;34:168.

2. Allen J, Gay B, Crebolder H, Heyman J, Svab I, Ram P, et al. A definição europeia de Medicina Geral e Familiar (Clínica Geral/Medicina Familiar). Rev Port Med Geral Fam. 2005;21:511-6.

3. Carmo H. A actualidade do desenvolvimento comunitário como estratégia de intervenção social. Actas da 1a conferência sobre

desenvolvimento comunitário e saúde. Lisboa: Instituto Universitário de Ciências Psicológicas, Sociais e da Vida; 2001.

4. da Silva MM. Fases de um processo de desenvolvimento comunitário. Análise Social. 1963;1:538-58.

5. Bispo Júnior J, Morais M. Participação comunitária no enfrentamento da COVID-19: entre o utilitarismo e a justiça social. Cad Saúde Pública. 2020;36:e00151620.

\section{Mafalda CARVALHEIRO $\square^{1,2}$, Cátia SÁ GUERREIRO ${ }^{2}$}

1. Unidade de Saúde Familiar Ouriceira. Ericeira. Portugal.

2. Instituto de Higiene e Medicina Tropical. Universidade NOVA de Lisboa. Lisboa. Portugal.

Autor correspondente: Mafalda Carvalheiro. mafalda.carvalheiro@gmail.com

Recebido: 03 de fevereiro de 2021 - Aceite: 04 de fevereiro de 2021 - Online issue published: 01 de abril de 2021

Copyright $\odot$ Ordem dos Médicos 2021

https://doi.org/10.20344/amp.15878 